\title{
Research on the Influencing Factors of Urban Economic Vitality in the Yangtze River Economic Zone Based on Factor Analysis
}

\author{
Hongming Wang, Ziqi Dai \\ School of Finance, Anhui University of Finance and Economics, Bengbu, China \\ Email:whm001025@163.com
}

How to cite this paper: Wang, H. M., \& Dai, Z. Q. (2021). Research on the Influencing Factors of Urban Economic Vitality in the Yangtze River Economic Zone Based on Factor Analysis. Open Journal of Social Sciences, 9, 516-528.

https://doi.org/10.4236/jss.2021.97037

Received: June 25, 2021

Accepted: July 26, 2021

Published: July 29, 2021

Copyright $\odot 2021$ by author(s) and Scientific Research Publishing Inc. This work is licensed under the Creative Commons Attribution International License (CC BY 4.0).

http://creativecommons.org/licenses/by/4.0/

(c) (i) Open Access

\begin{abstract}
The economic vitality of a city is an important factor in the ranking of a city's competitiveness. Based on the research of Lou Haimiao, Sun Qiubi and other scholars, this paper selects 10 indicators as indicators of urban economic vitality evaluation, and uses factor analysis to comprehensively evaluate the urban agglomerations in the Yangtze River Economic Zone. Using SPSS software to calculate the ranking of 11 provinces and cities in the Yangtze River Economic Zone, the research shows that the economic vitality of the Yangtze River Economic Zone gradually decreases from east to west. After analyzing the influencing factors of the economic vitality and competitiveness of the urban agglomerations in the Yangtze River Economic Belt through the gray correlation analysis model, the research results show that among the provinces and cities in the Yangtze River Delta Economic Belt, the number of business units has the greatest impact on the economic vitality and competitiveness of the city. Finally, it puts forward economic development suggestions for 11 provinces and cities in the Yangtze River Economic Belt.
\end{abstract}

\section{Keywords}

Urban Economic Vitality and Competitiveness, Factor Analysis Method, Grey Relational Analysis Method, SPSS

\section{Introduction}

Under the background of the rapid development of economic globalization and the accelerating process of urbanization, Chinese cities not only need to compete with domestic urban markets, but also need to face fierce international challenges. As the main battlefield of my country's ecological priority green devel- 
opment, the Yangtze River Economic Belt unblocks the domestic and international dual-cycle aorta, and leads the main force of high-quality economic development. Its high-quality development contributes to the coordinated development of regional economy, the rational integration of regional culture, and the comprehensive management of regional environment. Sharing the results of regional development, realizing the complementarity of various mechanisms within the region, accurately grasping the factors influencing the development of urban economic vitality and competitiveness and braking out the correct strategic positioning are particularly important for meeting the challenges of globalization. This paper analyzes the various factors that affect the urban economic vitality and their weights from different perspectives, and analyzes the impact of each indicator on the urban economic vitality and competitiveness and the impact of structural transformation on the urban economic vitality and competitiveness, providing constructive advice for urban development (Cheng, 2018).

On the basis of previous research, scholars such as Wang Zaiqi and Yu Shangwei revised the human green development index system. Taking the human green development of 9 provinces and 2 cities in the Yangtze River Economic Zone as the analysis object, they statistically analyzed 9 provinces in the Yangtze River Economic Zone. The city's human green development index explores the green development model of the Yangtze River Economic Belt; Zhou Zhengzhu, Wang Junlong and other scholars used 37 cities along the Yangtze River Economic Belt as the research objects, using factor analysis, comprehensive development index and other methods to explore the level of urbanization and comprehensive development of ecological environment. Chen Jiang measured the global value chain location of the manufacturing industry in each province and city of the Yangtze River Economic Belt and the degree of production service industry agglomeration, and conducted empirical analysis to study the extent of its impact on the manufacturing industry in the Yangtze River Economic Belt. This article will further improve the index system of the Yangtze River Economic Zone on the basis of the predecessors, and measure the weight of each factor's influence on the overall development of the Yangtze River Economic Zone, so as to make more effective suggestions for the high-quality, coordinated and integrated development of the Yangtze River Economic Zone (Du, 2019).

\section{Construction of the Evaluation System of Urban Economic Vigor}

\subsection{Index System Construction}

The World Organization for Economic Vitality and Sustainable Development defines the economic vitality of a city as: a region's economic competitiveness, adaptability, and its ability to attract private and public enterprises. According to the research of Lou Haimiao, Sun Qiubi and other scholars, in this article, ten indicators that affect the vitality and competitiveness of the city's economy have 
been determined, namely, per capita GDP, per capita GDP growth rate, operating surplus, permanent population, number of business units, per capita disposable income, and per capita disposable income growth. Per capita fiscal revenue, per capita education expenditure, and government fiscal expenditure as a percentage of GDP (He, Zhou, \& Zhu, 2020). In the process of urban economic vitality and influencing factors, this paper selects the number of enterprises, the registered capital of enterprises, and the number of permanent residents in the city as the first set of comparison series. The Yangtze River Economic Belt removes Shanghai and Chongqing after the two municipalities. The GDP of the three major industrial regions of the province is the second set of comparison series, see Table 1 (He, 2019).

\subsection{Data Source and Processing}

The data in this article comes from the data published by the statistical bureaus of various regions in the Yangtze River Economic Zone. The panel data from 2009 to 2018 are taken. For many data in different aspects of different cities, the data needs to be cleaned. The data is processed using EXCEL and SPSS software as follows: 1) Clear duplicate data and abnormal data in the data table; 2) Use interpolation to fill in missing data; 3) Data Standardized processing.

\section{Comprehensive Evaluation of the Economic Vitality of Provinces and Cities in the Yangtze River Economic Belt}

\subsection{Research Ideas}

Based on the research of historians, this paper improves and constructs the index system, uses factor analysis to reduce the original index system, selects the most significant common factors, and determines the weights, so as to comprehensively evaluate the economic vitality of the provinces and cities in the Yangtze River Economic Zone. The evaluation results are ranked and analyzed (He \& Ye, 2020).

Table 1. Urban economic vitality evaluation index system.

\begin{tabular}{ccc}
\hline Index & Index & Variable \\
\hline GDP per capita & Yuan/person & $X_{1}$ \\
GDP growth rate per capita & $\%$ & $X_{2}$ \\
Operating surplus & 100 million yuan & $X_{3}$ \\
permanent residents & $\mathrm{A}$ & $X_{4}$ \\
Number of business units & $\mathrm{A}$ & $X_{5}$ \\
Disposable income per capita & yuan & $X_{6}$ \\
Per capita disposable income growth rate & $\%$ & $X_{7}$ \\
Per capita fiscal revenue & Yuan/person & $X_{8}$ \\
Education expenditure per capita & yuan & $X_{9}$ \\
Government expenditure as a percentage of GDP & $\%$ & $X_{10}$ \\
\hline
\end{tabular}




\subsection{Research Methods}

In order to explore the comprehensive situation of the city's economic vitality and competitiveness, the factor analysis method is used to comprehensively evaluate it. The principle is to reduce the dimensionality of complex and diverse indicators, use a more significant common factor to represent the original indicators, and then calculate different The scores of the common factors and the total scores comprehensively reflect the city's economic vitality and competitiveness (Lei, Xu, \& Li, 2017).

\subsection{Model Establishment and Result Analysis}

According to the established index system, SPSS software is used to calculate and solve the model.

1) Adaptability test

The data needs to be tested for applicability before factor analysis. In KMO and Bartlett tests, both KMO and $\mathrm{P}$ are within the applicable range, which indicates that the selected indicators have passed the applicability test, and the data in this study are suitable Perform factor analysis, see Table 2.

2) Extract common factors

According to the common factor variance table, it reflects the extracted information of each original variable. Most of the indicators have been extracted about $90 \%$ of the information, indicating that most of the information of the original variable is preserved, and the established model can reflect the enterprise Refer to Figure 1 for the basic situation of credit risk (Li \& Yan, 2019).

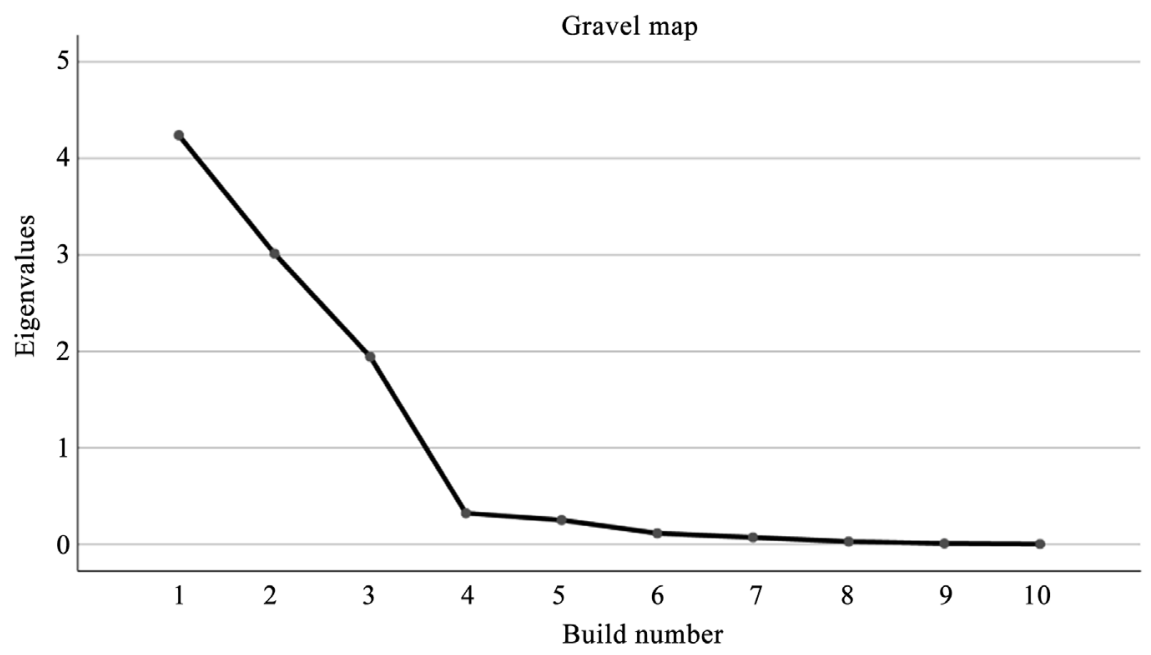

Figure 1. Crushed stone diagram.

Table 2. KMO and Bartlett test.

\begin{tabular}{cccc}
\hline \multirow{2}{*}{$\begin{array}{c}\text { KMO sampling } \\
\text { appropriateness number }\end{array}$} & \multicolumn{3}{c}{ Bartlett sphericity test } \\
\cline { 2 - 4 } & Approximate chi-square & degrees of freedom & significance \\
\hline 0.594 & 157.177 & 45 & 0 \\
\hline
\end{tabular}


In this article, based on the three common factors extracted from the gravel map, the variance contribution rates are $35.438 \%, 34.693 \%$, and $21.823 \%$, respectively, and the cumulative variance contribution rate reaches $91.953 \%$, see Table 3. Therefore, retaining the first 3 common factors can retain most of the information of the original variable.

3) The naming of common factors

After using the maximum variance method for factor rotation, the actual meaning of the common factor becomes clearer. Refer to Table 4 for the rotated component matrix. The first public factor has a large load on the per capita GDP, annual per capita disposable income of residents, per capita fiscal income, and per capita education expenditure. It reflects the overall situation, so it is named as the personal quality of life factor. The factor has a large load in operating surplus, permanent population, and the number of enterprises, which reflects the vitality of enterprises, so it is named enterprise vitality. The third factor has a large load on the growth rate of per capita regional product and the growth rate of annual per capita disposable income of the government in the proportion of GDP. It reflects the growth rate of each economy, so it is named the economic change rate factor.

4) Urban economic vitality rating and ranking

Assign the relative variance contribution rate of each common factor as the weight. Through calculation, the relative variance contribution rate of the first common factor is $38.54 \%$, the relative variance contribution rate of the second common factor is $37.73 \%$, and the relative variance contribution rate of the third common factor is $23.73 \%$.

According to the component score coefficient matrix, the score functions for calculating the personal quality of life factor, enterprise vitality factor and economic change rate factor are:

Table 3. Feature root and variance contribution rate.

\begin{tabular}{|c|c|c|c|c|c|c|c|c|c|}
\hline \multirow{2}{*}{ ingredient } & \multicolumn{3}{|c|}{ Initial eigenvalue } & \multicolumn{3}{|c|}{ Extract the sum of squares of the load } & \multicolumn{3}{|c|}{ Rotating load sum of squares } \\
\hline & total & Variance $\%$ & Accumulation $\%$ & total & Variance \% & accumulation\% & total & Variance $\%$ & accumulation $\%$ \\
\hline 1 & 4.239 & 42.395 & 42.395 & 4.239 & 42.395 & 42.395 & 3.544 & 35.438 & 35.438 \\
\hline 2 & 3.012 & 30.123 & 72.518 & 3.012 & 30.123 & 72.518 & 3.469 & 34.693 & 70.13 \\
\hline 3 & 1.944 & 19.435 & 91.953 & 1.944 & 19.435 & 91.953 & 2.182 & 21.823 & 91.953 \\
\hline 4 & 0.323 & 3.229 & 95.182 & & & & & & \\
\hline 5 & 0.251 & 2.512 & 97.694 & & & & & & \\
\hline 6 & 0.115 & 1.152 & 98.846 & & & & & & \\
\hline 7 & 0.072 & 0.724 & 99.57 & & & & & & \\
\hline 8 & 0.029 & 0.293 & 99.863 & & & & & & \\
\hline 9 & 0.01 & 0.098 & 99.961 & & & & & & \\
\hline 10 & 0.004 & 0.039 & 100 & & & & & & \\
\hline
\end{tabular}


Table 4. Component matrix after rotation.

\begin{tabular}{|c|c|c|c|}
\hline \multirow{2}{*}{ index } & \multicolumn{3}{|c|}{ main ingredient } \\
\hline & 1 & 2 & 3 \\
\hline GDP per capita in that year & 0.761 & 0.543 & 0.316 \\
\hline Growth rate of GDP per capita in that year & 0.076 & 0.083 & 0.961 \\
\hline Operating surplus & 0.188 & 0.929 & 0.096 \\
\hline permanent residents & -0.551 & 0.679 & 0.351 \\
\hline Number of companies & 0.081 & 0.939 & 0.182 \\
\hline Annual per capita disposable income of residents & 0.909 & 0.351 & -0.1 \\
\hline Annual residents' per capita disposable income growth rate & -0.023 & 0.04 & 0.958 \\
\hline Per capita fiscal revenue & 0.949 & -0.015 & 0.147 \\
\hline Education expenditure per capita & 0.935 & -0.073 & -0.076 \\
\hline Government expenditure as a percentage of GDP & -0.1 & -0.912 & 0.191 \\
\hline $\begin{aligned} Y_{1}= & 0.194 X_{1}^{*}+0.020 X_{2}^{*}+0.006 X_{3}^{*}-0.19 \\
& +0.246 X_{6}^{*}-0.007 X_{7}^{*}+0.278 X_{8}^{*}+0.2\end{aligned}$ & $\begin{array}{l}X_{4}^{*}-0.0 \\
6 X_{9}^{*}+0\end{array}$ & $\begin{array}{l}6 X_{5}^{*} \\
19 X_{10}^{*}\end{array}$ & $(1)$ \\
\hline $\begin{aligned} Y_{2}= & 0.103 X_{1}^{*}-0.056 X_{2}^{*}+0.272 X_{3}^{*}+0.21 \\
& +0.069 X_{6}^{*}-0.064 X_{7}^{*}-0.067 X_{8}^{*}-0 .\end{aligned}$ & $\begin{array}{l}X_{4}^{*}+0.2 \\
6 X_{9}^{*}-0\end{array}$ & $\begin{array}{l}3 X_{5}^{*} \\
94 X_{10}^{*}\end{array}$ & $(2)$ \\
\hline $\begin{aligned} Y_{3}= & 0.109 X_{1}^{*}+0.455 X_{2}^{*}-0.029 X_{3}^{*}+0.11 \\
& -0.074 X_{6}^{*}+0.456 X_{7}^{*}+0.074 X_{8}^{*}-0.0\end{aligned}$ & $\begin{array}{l}X_{4}^{*}+0.0 \\
8 X_{9}^{*}+0\end{array}$ & $\begin{array}{l}2 X_{5}^{*} \\
65 X_{10}^{*}\end{array}$ & $(3)$ \\
\hline
\end{tabular}

among them: $X_{1}^{*} \sim X_{10}^{*}$ are the normalized values of the original data.

The comprehensive score function is obtained by calculating the relative variance contribution rate:

$$
Y=0.3854 Y_{1}+0.3773 Y_{2}+0.2373 Y_{3}
$$

Solve to get the comprehensive score and ranking of each region, see Table 5: As can be seen from Table 5, the top 3 regions are distributed in Shanghai, Jiangsu, Zhejiang, and the bottom 3 regions are in Sichuan, Jiangxi, and Guizhou.

\section{Analysis of Influencing Factors of Urban Economic Vitality}

\subsection{Research Ideas}

1) Analysis of factors affecting indicators

Use the method of grey relational analysis to analyze the influencing factors of the economic vitality and competitiveness of the Yangtze River Economic Zone. Perform gray correlation analysis based on the data in the attached attachments, calculate the gray correlation coefficient and gray correlation degree of each factor and compare them to draw conclusions. Select the appropriate index system based on the conclusion target. This paper selects three sets of data from the provinces and cities of the Yangtze River Economic Belt (2009-2018), the number of business units, the registered capital of the company, and the permanent 
Table 5. Comprehensive scores and rankings of each region.

\begin{tabular}{ccc}
\hline area & overall ratings & total ranking \\
\hline Shanghai & 28.89 & 1 \\
Jiangsu & 26.71 & 2 \\
Zhejiang & 23.46 & 3 \\
Hubei & 14.01 & 4 \\
Chongqing & 13.34 & 5 \\
Hunan & 12.24 & 6 \\
Anhui & 11.59 & 7 \\
Sichuan & 11.27 & 8 \\
Jiangxi & 10.67 & 9 \\
Guizhou & 8.37 & 10 \\
Yunnan & 8.08 & 11 \\
\hline
\end{tabular}

population of the city, and calculates the degree of gray correlation between the three and analyzes the results (Lou \& Sun, 2005).

2) Analysis of factors affecting economic transformation

It also uses the grey relational analysis method to analyze the long-term and short-term impacts of the economic transformation on the economic vitality and competitiveness of the Yangtze River Economic Belt.

Economic transformation refers to the distribution of economic resources and changes in development models, including changes in development methods, development factors and other factors. Judging from historical experience, both developing and developed countries have developed a road to rapid economic development in the course of economic transformation. From the period of the "Ninth Five-Year Plan", China has proposed that China want economic transformation and upgrading.

My country's economic transformation is divided into economic structural transformation and institutional transformation. The institutional transformation means that my country's economic system is gradually transformed and upgraded in the direction of a market economic system. The thematic investment purpose behind it is that China will complete its system transformation and achieve system innovation within a certain period of time. The economic structure transformation refers to the transformation of my country's main economic structure from a traditional agricultural and rural country to a modern industrial country. The purpose is to change the status of a domestic economic structure and realize the transformation of economic growth mode. The economic structure includes the three major industrial structures, the technical structure of heavy industry, the structure of market supply and demand, the organizational structure of enterprises, and so on. Therefore, the transformation of economic structure includes the adjustment of technological structure and the structural transformation of the three major industries $(\mathrm{Lu}$, 
2007).

Therefore, this article selects the type of structural transformation in economic transformation, and uses its representative industrial structure transformation to represent economic transformation, and industrial structure transformation is often reflected in the regional GDP of the three major industries. Therefore, this article selects the Yangtze River Economic Belt to remove Shanghai. The GDP of the three major industries in the nine provinces behind the two municipalities directly under the Central Government of Chongqing is used as a sub-sequence, and the economic vitality scores of each region are used as the parent sequence for grey correlation analysis. Explore the correlation coefficient and gray correlation degree, and get the influence of economic transformation and the economic vitality of the Yangtze River Economic Belt.

\subsection{Research Methods}

Grey system theory mainly uses limited data to find unknown system connections. As a multi-attribute decision-making tool, it can calculate the data of various factors in incomplete data, search for the relevance of random factor sequences, and find the main influencing factors on the results (Shao, 2019).

\subsection{Model Establishment and Solution}

1) Determine the reference data column

The reference data column should be an ideal comparison standard. The reference data column can be constituted by the optimal value (or worst value) of each index, or other reference values can be selected according to the evaluation purpose. In this article, the urban economic vitality that has been obtained is selected as the reference sequence $X_{0}$, which is recorded as:

$$
X_{0}^{\prime}=\left(x_{0}^{\prime}(1), x_{0}^{\prime}(2), \cdots, x_{0}^{\prime}(m)\right)
$$

The comparison numbers are listed as the number of business units $X_{1}$, the company's registered capital $X_{2}$, and the city's permanent population $X_{3}$ :

$$
X_{j}^{\prime}=\left\{X_{j}^{\prime}(i) \mid j=1,2, \cdots, n ; i=1,2, \cdots, m\right\}
$$

2) Dimensionless processing

The indicator data is dimensionless. In this study, the mean value method is used for dimensionless processing. The calculation formula is:

$$
X_{i}=\frac{X_{i}^{\prime}}{\overline{X_{i}^{\prime}}}
$$

3) Calculate the gray correlation coefficient

Calculate the gray correlation coefficient according to the formula, the formula is as follows:

$$
\xi_{i}(k)=\frac{\min _{i} \min _{k}\left|x_{0}(k)-x_{i}(k)\right|+\rho \cdot \max _{i} \max _{k}\left|x_{0}(k)-x_{i}(k)\right|}{\left|x_{0}(k)-x_{i}(k)\right|+\rho \cdot \max _{i} \max _{k}\left|x_{0}(k)-x_{i}(k)\right|}
$$


where $\rho$ is the resolution coefficient, $0<\rho<1$. If $\rho$ is smaller, the difference between correlation coefficients is larger, and the distinguishing ability is stronger. In this article, $\rho$ is taken as 0.5 .

4) Calculate the gray correlation degree

a) Solving the impact of economic transformation

According to the correlation degree of each observation object, the analysis result is obtained.

$$
r_{0 i}=\frac{1}{m} \sum_{k=1}^{m} \xi_{i}(k)
$$

Solving with EXCEL, substituting into the formula can get the gray correlation coefficient and gray correlation degree, see Table 6.

According to the gray correlation coefficient, the solution can be continued, and the gray correlation degree of each index can be obtained, see Table 7 .

b) Structural transformation impact solving

Solving with EXCEL, and substituting into the formula, the gray correlation coefficient and gray correlation degree can be obtained, see Table 8 .

Continue to solve according to the gray correlation coefficient, and get the gray correlation degree of each index, see Table 9.

\subsection{Result Analysis}

1) Result analysis of index influencing factors

Table 6. Indicator gray correlation coefficient table.

\begin{tabular}{ccc}
\hline$X_{1}$ & $X_{2}$ & $X_{3}$ \\
\hline 0.56867 & 0.45881 & 0.33486 \\
0.57215 & 0.39664 & 0.75166 \\
0.91746 & 0.78139 & 0.58638 \\
0.77794 & 0.88473 & 0.64780 \\
0.72376 & 0.65132 & 0.70341 \\
0.70640 & 0.69598 & 0.47295 \\
1.00000 & 0.80738 & 0.86186 \\
0.98643 & 0.95885 & 0.66836 \\
0.75559 & 0.96991 & 0.93081 \\
0.88764 & 0.85820 & 0.70836 \\
0.84495 & 0.81109 & 0.55953
\end{tabular}

Table 7. Indicator gray correlation table.

\begin{tabular}{cccc}
\hline index & $\begin{array}{c}\text { Number of business units } \\
r_{1}\end{array}$ & $\begin{array}{c}\text { Enterprise registered capital } \\
r_{2}\end{array}$ & $\begin{array}{c}\text { Urban population } \\
r_{3}\end{array}$ \\
\hline Correlation & 0.79463 & 0.75221 & 0.65691 \\
\hline
\end{tabular}


Table 8. Industrial gray correlation coefficient table.

\begin{tabular}{ccc}
\hline Agriculture & industry & service industry \\
\hline 0.5120 & 0.4626 & 0.4535 \\
0.3353 & 0.8617 & 0.6868 \\
0.8598 & 0.7622 & 0.9928 \\
0.8184 & 0.6522 & 0.7892 \\
0.6726 & 0.9168 & 1.0000 \\
0.7329 & 0.8477 & 0.9221 \\
0.4171 & 0.6636 & 0.8019 \\
0.6700 & 0.8034 & 0.7451 \\
0.8100 & 0.6717 & 0.6735 \\
\hline
\end{tabular}

Table 9. Grey correlation degree.

\begin{tabular}{cccc}
\hline index & Agriculture & industry & service industry \\
\hline Grey relational degree & 0.6323 & 0.7140 & 0.7850 \\
\hline
\end{tabular}

By calculating the gray correlation degree to each indicator, as shown in the above table, the number of enterprise units $r_{1}=0.79463$, the registered capital of the enterprise $r_{2}=0.75221$, and the urban permanent population $r_{3}=0.65691$, where $r_{1}>r_{2}>r_{3}$ can be obtained. The number of business units in a region has the greatest impact on the economic vitality of the city, which means that more business registrations can stimulate the economic vitality of the region to a greater extent; the registered capital of enterprises has a greater impact on the economic vitality of the city, while the urban permanent population The correlation degree between the number and the urban economic vitality is 0.65691, which also has a certain influence on the regional economic vitality, but it is not as large as the number of registered enterprises and the number of registered capital of enterprises.

2) Analysis of the impact of structural transformation

As shown in the above table, the gray correlation degree of each index obtained by calculation, the primary industry $r_{1}=0.6323$, the secondary industry $r_{2}$ $=0.7140$, and the tertiary industry $r_{3}=0.7850$, where $r_{1}<r_{2}<r_{3}$, we can get The tertiary industry has the greatest impact on the economic vitality of the city, which means that the tertiary industry, which is based on the service industry, can stimulate the economic vitality of the region; the secondary industry has a greater impact on the economic vitality of the city, while the primary industry The correlation with the urban economic vitality is 0.6323 , which also has a certain influence on the regional economic vitality, but it is not as large as the secondary and tertiary industries (Wang, 2015).

Xiao Zhang now loves the culture of Chinese medicine, and her mission is to spread the culture of Chinese medicine. She gets along well with students from the Mainland. She has joined the Hong Kong Alumni Association and told her 
relatives and friends about her studies in the Mainland.

\section{Suggestions for the Development of 11 Provinces and Cities in the Yangtze River Economic Belt}

\subsection{Attract Migrants}

The conclusion drawn from this shows that the larger the population, the more it can stimulate economic development, thereby enhancing the vitality of the regional economy. Attracting migrants can be achieved through a variety of methods, such as reducing housing prices and attracting migrants to buy houses again; vigorously develop high-quality education and create an educational highland; build a civilized city and create a livable urban environment to attract high-quality population Wait (Wang, 2020).

\subsection{Ensure the Number of Employed People and Reduce the Unemployment Rate}

For some regions, the reduction in national income is due to unemployment. While the economic growth rate slows down, it will also increase social welfare expenditures, and will cause financial difficulties and increase social instability. Therefore, it is very important to ensure the number of employees. The government can stimulate aggregate demand by implementing expansionary fiscal policies and monetary policies, thereby reducing cyclical unemployment as much as possible. And through the establishment of a variety of employment service agencies, comprehensive employment services; vocational training is gradually cultivated as the first measure to reduce unemployment; reform of the system, from inactive relief to more active employment, etc., reduce the natural unemployment rate . A certain employment rate can promote economic development, increase the number of enterprises, and further increase employment to create a virtuous circle (Yidi, 2019).

\subsection{Adjust the Industrial Structure}

Improving the quality of the industrial structure is very important for improving the vitality of the regional economy. The process of promoting a more reasonable industrial structure and the development of industrial structure requires the realization of industrial structure and various structures, such as: the structure of resource supply, the structure of technology, and the structure of demand. According to the non-subjective proportional relation of the economic relations of the technology industry, following the requirements of the proportionality of the secondary production process, it promotes the coordinated development of various industries of a certain economy, so that each industry can adapt to the progress of the entire regional economy. It can be seen from the model results that the tertiary industry in the Yangtze River Economic Belt has developed rapidly in recent years, and optimizing the structure of the three industries will help the various production sectors of the regional economy to connect with 
each other. In the development of the three industrial structures, at the level of speed, adjustments are accelerated, methods are changed, and the primary industry is upgraded. At the same time, the secondary industry develops characteristics and the tertiary industry stabilizes the foundation and takes it to a higher level (Zhang, 2019).

\subsection{Improve Environmental Quality and Adhere to Green Development}

In the context of the prevailing green economy, we must profoundly interpret "green water and green mountains are golden mountains and silver mountains" (Zhou, 2007). According to the third question, environmental factors contribute the most to regional economic vitality. In order to ensure the continued improvement of the ecological environment, the Northeast region should continue to increase pollution prevention and control efforts, promote the development of green industry, rationally treat and utilize industrial waste, and accelerate the green transformation.

\section{Analysis Conclusion}

In summary, based on the research of Lou Haimiao, Sun Qiubi and other scholars, this paper selects 13 indicators as indicators of urban economic vitality evaluation, and uses factor analysis to comprehensively evaluate the urban agglomerations in the Yangtze River Economic Zone. Using SPSS software to calculate the ranking of 11 provinces and cities in the Yangtze River Economic Zone, the research shows that the economic vitality of the Yanchang River Economic Zone gradually decreases from east to west. After analyzing the influencing factors of the economic vitality and competitiveness of the urban agglomerations in the Yangtze River Economic Belt through the gray correlation analysis model, the research results show that among the provinces and cities in the Yangtze River Delta Economic Belt, the number of business units has the greatest impact on the economic vitality and competitiveness of the city. This article puts forward development suggestions for 11 provinces and cities in the Yangtze River Economic Belt, including: first, attract migrants; second, ensure employment and reduce unemployment; third, adjust industrial structure; fourth, improve environmental quality and persist in green development.

\section{Conflicts of Interest}

The authors declare no conflicts of interest regarding the publication of this paper.

\section{References}

Cheng, J. (2018). The Source of Urban Vitality: The Systemic Impact of Floating Population on Urban Economic Development. Urban and Environmental Research, No. 4, 54-69.

Du, W. (2019). Research on Influencing Factors of Road Permeable Concrete Macro Per- 
formance Based on Grey Relational Analysis Method. Roadbed Engineering, No. 6, 134-139.

He, G., Zhou, Y. F., \& Zhu, Y. N. (2020). Research on the Measurement of Industrial Transformation and Upgrading in Beijing-Tianjin-Hebei Region and Its Economic Effects. Statistics and Decision, No. 1, 86-90.

He, R. Q. (2019). Research on the Evaluation of the Economic Vitality of Cities in the Pearl River-Xijiang Economic Belt. Guangxi Normal University.

He, X. L., \& Ye, L. G. (2020). A Economic Correlation, Spatial Spillover and Economic Growth of the Urban Agglomeration in the Yangtze River Economic Belt. Modern Finance and Economics (Journal of Tianjin University of Finance and Economics), 40, 16-28.

Lei, S. Y., Xu, D. Y., \& Li, Z. R. (2017). Comprehensive Evaluation and Analysis of the Urban Vitality of Cities in Sichuan Province. Economic Forum, No. 9, 26-29.

Li, L., \& Yan, Z. Z. (2019). Tianjin Economic Restructuring and Industrial Transformation and Upgrading Countermeasures. Tianjin Economy, No. 12, 3-5.

Lou, H. M., \& Sun, Q. B. (2005). Research on the Evaluation of Economic Vitality of Various Provinces in My Country Based on Factor Analysis. Journal of Fuzhou University (Philosophy and Social Sciences Edition), No. 3, 32-35.

Lu, X. L., \& Guo, W. S. (2007). Comprehensive Evaluation Index System of Urban Economic Vitality. Statistics and Decision, No. 11, 77-78.

Shao, Y. Y. (2019). An Empirical Study on the Relationship between China's Industrial Structure Optimization and Economic Growth. China Collective Economy, No. 36, 20-21.

Wang, L. M., \& Deng, L. (2015). An Empirical Study on the Optimization and Upgrading of My Country's Industrial Structure: Taking the Yangtze River Economic Belt as an Example. Economic Issues, No. 5, 39-43.

Wang, Q. S. (2020). Research on China's Economic Modernization Transition under the New Normal. China Business Review, No. 1, 228-231.

Yidi (2019). Evaluation on the Development Policy of the Yangtze River Economic Belt. Chinese Market, No. 34, 8-15.

Zhang, K. Y. (2019). Analysis on the Status Quo of Urban Vitality Development in Beijing-Tianjin-Hebei Based on Corporate Influence. Industry and Technology Forum, 18, 87-88.

Zhou, X. W. (2007). Research and Application of Grey Correlation Degree. Jilin University. 